\title{
The Mediterranean Diet as a Factor in Environmental
}

\section{Education}

\author{
Georgios J. Tsikalakis
}

Laboratory of Dietetics \& Human Body Composition, Department of Nutrition \& Dietetics T.E.I. of Crete, University of Applied Sciences Tripitos, Sitia, Crete 723 00, Greece

\begin{abstract}
The Mediterranean diet is an excellent nutritional model. Another feature of the Mediterranean diet is that it is a cultural model with common features for all peoples of the Mediterranean. But apart from health and culture, the Mediterranean diet, according to studies, also helps to protect the natural environment. As an environmental asset, therefore, the Mediterranean diet can be a teaching approach to environmental education. This study aims to raise awareness of the issue of the Mediterranean diet in the training and implementation of an environmental project at all levels of education.
\end{abstract}

Key words: Mediterranean diet, environmental education, environment, health.

The concept of Mediterranean diet is extremely timely nowadays, as more and more health scientists, as well as informed citizens, find that the typical diet of the Cretans gathers the elements that make it a healthy diet. In this paper, it presented all necessary details about Mediterranean diet and its connection with the environment, but also a teaching proposal for an environmental project.

\section{What Is the Mediterranean Diet?}

The conclusion that the Cretan diet is a special case of dietetic habit with excellent results was first documented by the Rockefeller study in 1948, and then the very important, well documented study of Professor Ancel Keys of the University of Minnesota, held in the decade 1950 and 1960, included 11,500 people from 7 countries. This study is known as "The Study of the 7 Countries" [1]. These are 16 subgroups of population, namely 3 population groups from Italy, 5 groups from the former Yugoslavia, 2 from Japan, 2 from Finland, one from the Netherlands, one from the USA and 2 from Greece (Crete-Corfu). On the basis

Corresponding author: Georgios J. Tsikalakis, Ph.D., research fields: food policy. of the results, discussions started after observing that the inhabitants of the Mediterranean countries had better health than those of other countries. For Crete, the results were impressive since the lowest mortality from coronary heart disease and other heart disease was observed compared to other countries [2].

Why is it called "Mediterranean" rather than "Cretan” ? The story began in 1987 with US Senator Dun Gifford. The same enthusiasm from the traditional Chinese diet was founded in 1988 in Boston by the Oldways Foundation, which in turn used the term "Mediterranean" diet by presenting the now known food pyramid. Later, the institute, in collaboration with Harvard University, established a nutrition program for doctors and organized conferences in Europe for this purpose. The idea was very popular from the beginning and was immediately adopted by the International Olive Oil Council, which focused on the common use of olive oil as a basic fatty food. Thus, despite the fact that the nutrition of the Mediterranean peoples is very different, even in Greece itself, since 2000 the International Conference on Mediterranean diet in London has issued a joint declaration accepting the term "The traditional Mediterranean term diet was used to determine the 
dietary habits that featured certain areas of the Mediterranean in the early 1960s, such as Crete, certain parts of Greece and southern Italy, and include a range of foods" [1].

The Cretan diet is known from the sources already from the Bronze Age with finds such as animal bones, fruit, seeds and leaves. Olive oil has been a key element in all periods and in the diet of the Cretans. In general, the "Mediterranean" diet includes plenty of plant foods, fresh seasonal products, fresh fruit, olive oil as a source of fat, dairy products, small to moderate portions of fish and poultry, up to 4 eggs a week, small quantities of red meat and red wine.

In 2010, all of the above specific features of the Mediterranean diet observed to all the peoples, more or less, of the Mediterranean Sea, were recognized by UNESCO as a cultural asset for humanity and included in the list of the intangible cultural heritage of the organization [3].

\section{The contribution of the Mediterranean Diet to Health}

The Mediterranean diet-rich in whole grain foods instead of processed foods-has also been shown to help the body in many other ways. Five of the main benefits of the Mediterranean diet to health are:

\subsection{Heart Protection}

Since the publication of the first results of the seven countries study was much discussion at the conclusion showed that the inhabitants of the Mediterranean countries, have generally better health than the inhabitants of the northern countries (Fig. 1). Especially in Crete, what was happening was impressive. Cardiovascular diseases were almost unknown [2]. This is confirmed by a 2015 study by the American College of Cardiology that has attended over 2,500 Greek adults for more than 10 years. Those who followed the Mediterranean diet were 47\% less likely to develop heart disease than their peers who were not loyal to a Mediterranean diet plan.
Interestingly, researchers found that attachment to nutrition provided greater protection than physical exercise [4].

\subsection{Better Brain Activity}

A 2016 survey found that eating whole grain and "good" fat can improve brain function, slow down the rate at which brain function decreases, and reduce the likelihood of Alzheimer's disease [5].

\subsection{Weight Loss}

Many studies have focused on the ability of the Mediterranean diet to help people lose unwanted pounds. In 2011, an article was published in the journal Metabolic Syndrome and Related Disorders, which found that participants who followed a Mediterranean diet program lost about $4 \mathrm{~kg}$ more compared to the control group participants. The results were even more significant when the participants took part in the exercise program and adopted the Mediterranean diet for more than six months [6].

\subsection{Preventing Chronic Diseases}

It is now known to link the Mediterranean diet to the prevention of chronic diseases. First, followers tend to have less body fat and a lower risk of metabolic syndrome. Secondly, Mediterranean diet and consumption of extra virgin olive oil can also reduce the risk of developing diabetes [7].

\subsection{Increased Longevity}

Already from the study of the seven countries, the Mediterranean diet was linked to longevity, but a later study found cellular differences between the women who followed the Mediterranean diet program and those who ate more meat and dairy products, especially with regard to the length of the telomere, which is DNA sequences found at the end of the chromosomes. The length of the telomere has an interesting relationship with aging: small telomeres have been associated with a shorter life, while long 


\section{Study of 7 countries for coronary heart disease mortality per 100,000 inhabitants}

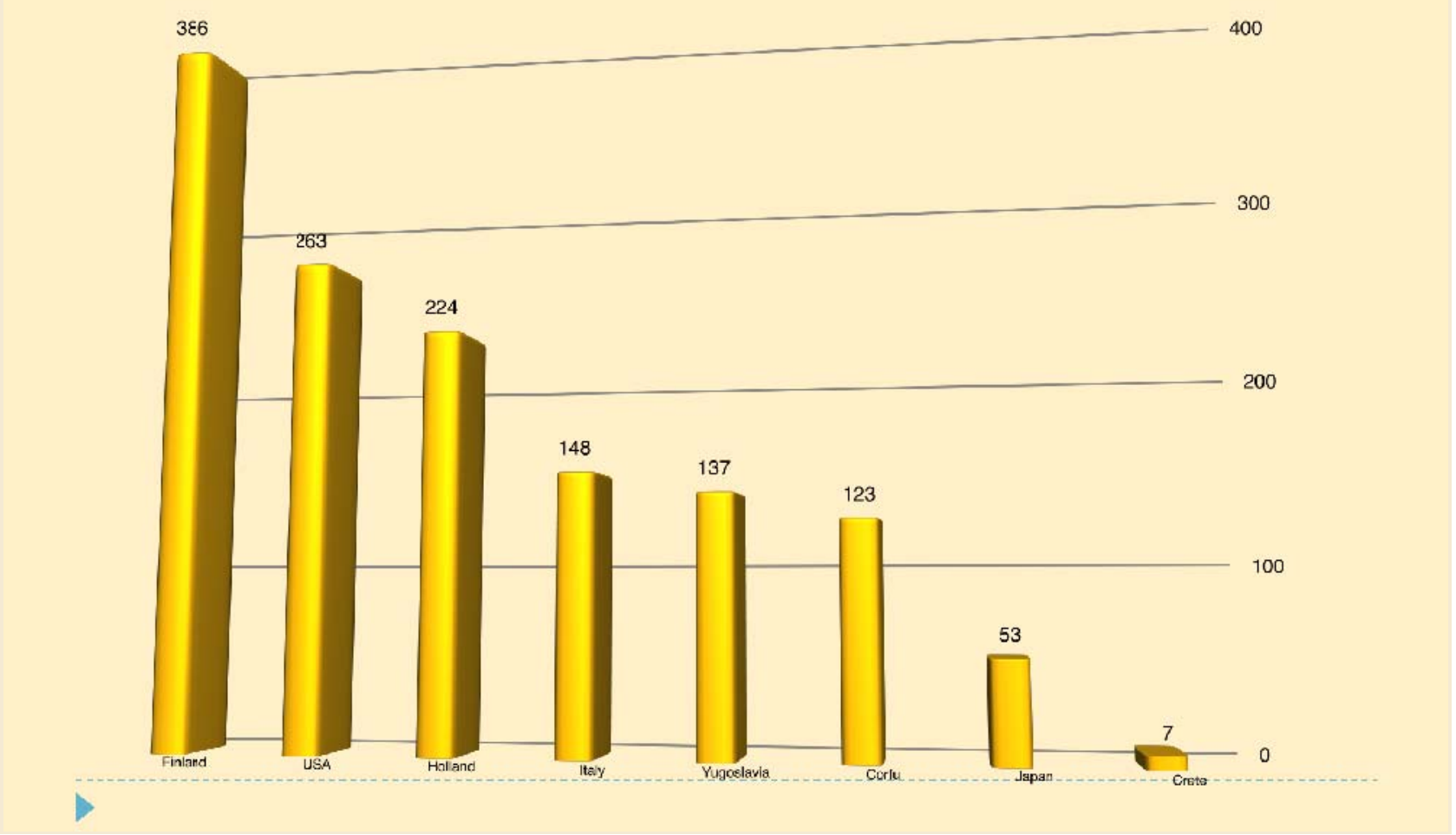

Fig. 1 Study of 7 countries-heart disease mortality.

telomere may be equivalent to longer life. Mediterranean diet fans had larger telomere in length [8].

\section{The Footprint of Food in the Natural Environment}

How does food affect the natural environment?

\subsection{Agriculture and Food Production}

The most complex relationship to the environment with positive and negative impacts since agricultural activity encompasses a series of biophysical and space-related processes [9] (the intensive cultivation, the use of chemical fertilizers and pesticides, and the water wastage).

\subsection{Livestock Farming}

The burden on the environment through livestock farming is due to the need to produce red meat. This creates difficulties because the need for more and more production of animals that will end up in the food market is created. And as long as a happy cow is a beautiful picture on paintings or photo albums there are basically consequences. The cow... digs! Because of fermentations in its digestive system, like any ruminant, it produces $\mathrm{CH}_{4}$ (methane), a gas 23 times more harmful than carbon dioxide in terms of greenhouse effect. The composition of the feed affects the way it breaks down in the ruminant intestines and therefore the amount of $\mathrm{CH}_{4}$ produced, but the animal itself plays a catalytic role. Typically, a cow can produce between 100 and 200 liters of $\mathrm{CH}_{4}$ daily; this is also the case with other animals to a lesser extent, for example a sheep produces just 30 liters of $\mathrm{CH}_{4}$ [10]. Chemical fertilizers for animal feed and livestock manure are responsible for the release of significant amounts of nitrogen monoxide $\left(\mathrm{N}_{2} \mathrm{O}\right)$, which is 296 times more potent than carbon dioxide $\left(\mathrm{CO}_{2}\right)$ in its ability to bind 
heat, and remains in the atmosphere for an average of 114 years. Livestock farming is responsible for $65 \%$ of man-made nitrogenous nitrous oxide, mainly from manure [11].

Livestock consumes large quantities of fresh water, which is irrigated for feed production. It is estimated that each liter of cow's milk accounts for 990 liters of water [12]. The more technologically advanced the livestock farming area is, the more it contributes, due to the infrastructure and energy-intensive equipment it uses in climate change. The problem is not so much from the direct consumption of energy for the use of agricultural machinery, but from the indirect, for the production of animal feed, fertilizers, seeds and the construction of infrastructure. Thus, an average of one liter of cow's milk requires 250 grams of oil equivalent, while for a pound of beef 1,550 grams in oil equivalents, where 1 equivalent of oil corresponds to 0.75 liters of gasoline. Worldwide livestock farming intensifies the problem of pollution (gas emissions, local nitrogen and phosphorus surpluses, groundwater pollution). We must not ignore the fact that livestock waste is burdened with pathogens, while extensive use of antibiotics has mutated and enhanced the defense of their dispersing microorganisms in the environment [13].

\subsection{The Food Industry}

Food is no longer just the productive sector, food is now a commercial and industrial product. Increased interest in issues such as nutrition, food safety, ecology, animal welfare and environmental sustainability affects the evolution of demand for food products. The consumer is now considered the primary driving force in the global food market. Demand for the various types of high value added agro-food products (e.g. organic, organic etc.) affects the food business strategy [14], and has altered food from a basic need, a product of commercial exploitation of a consumer society. It is certain that the more processed foods the modern man consumes, the more energy needs of the food industry are being grown to meet this need.

\subsection{Transport and Distribution of Food to the Consumer}

Food transport requires the use of resources and resources. Shipping, e.g. creates threats to the environment both on inland waterways and in the ocean. These problems arise from five major sources: (i) routine discharges of oil bilge and leachate from shipping; (ii) the disposal of non-biodegradable solid

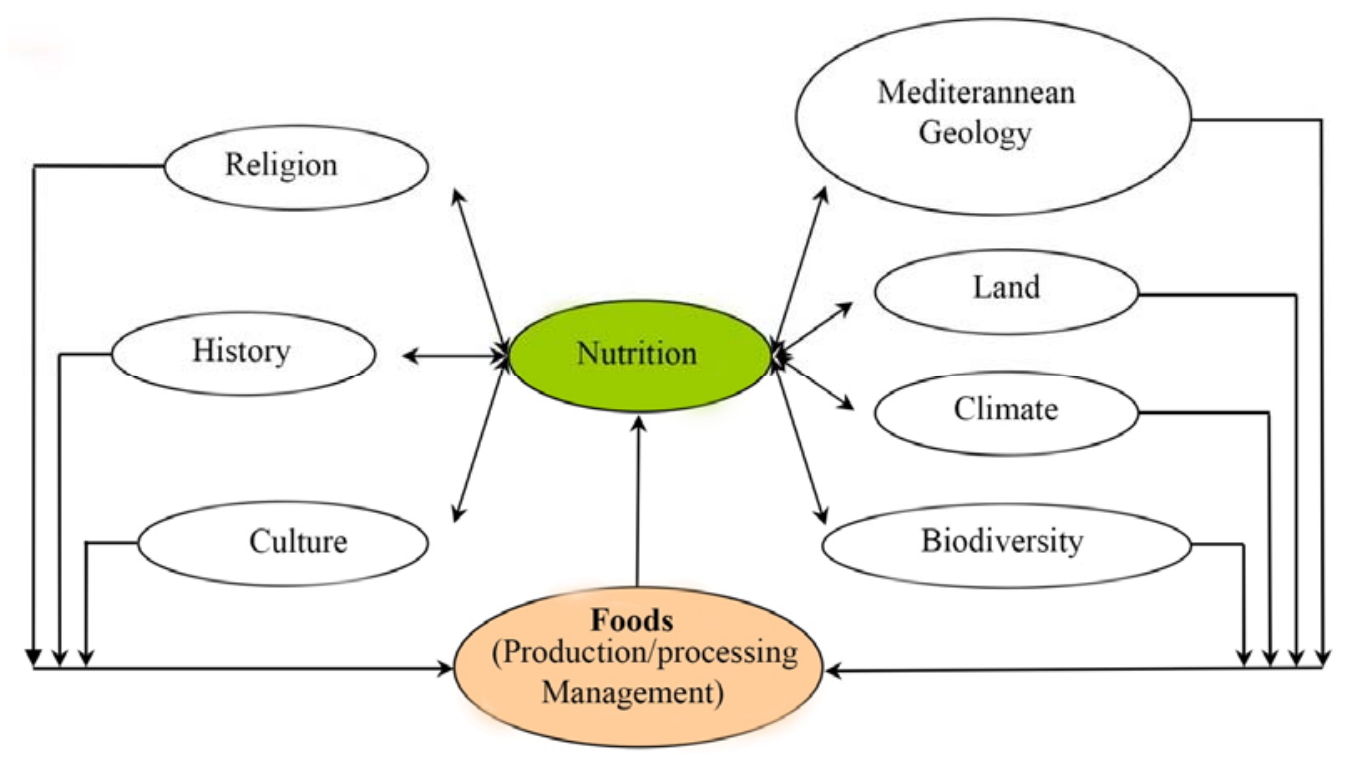

Fig. 2 Connection nutrition and environment. 
waste in the ocean; (iii) accidental leakage of oil, toxic or other cargo or fuel at ports and during the journey; emissions from the sources of supply of vessels; (iv) construction and management of ports and inland canals; (v) exotic species transported on board [15]. Consequently, the transfer tends to exacerbate an existing problem as it attempts to solve another.

3.5 Finally, the Loss and Wastage of Food Remains the Problem

A global problem, which in recent years has occupied a major place in public life and on the political agenda. Its importance is even expected to increase further, given in particular the need to feed the ever-growing world population. According to current estimates, around one third of food produced for consumption is wasted or lost globally, which entails economic and environmental costs. The problem of food waste affects every link in the food chain and, therefore, measures should be targeted at the entire chain length and aimed at potential benefits for all involved. Emphasis should be placed on prevention, as the benefits of avoiding waste are overriding those of dealing with it at a later stage [16].

\section{How Does the Mediterranean Diet Contribute to the Protection of the Natural Environment?}

In a Tufts study conducted, 33 million motor cars were found to be equivalent to exhaust fumes produced by food preparation. Also, the study found that the production of red meat, that is the burgers in our dish, contributes $36 \%$ to greenhouse gases [17]. So, if we limit our diet to animal proteins and we prefer proteins of plant origin that the Mediterranean diet also proposes, we will also help reduce greenhouse gases, and thus improve climatic conditions.

In addition, according to a study by the National Institute of Health of the United States, conducted in 548,699 people for 17 years and announced in early
July at a conference of the American Thoracic Surgery Society, it finds that those who follow Mediterranean diet are protected from exposure to air pollution due to antioxidants which contain through fruits and vegetables [18].

In conclusion, according to the study results published in Environmental Health magazine, which concerned the maintenance of this diet in Spain, the Mediterranean diet if applied to the whole population could reduce greenhouse gas emissions (72\%), land use (58\%), energy consumption (52\%) and to a lesser extent water consumption (33\%). On the other hand, commitment to a Western dietary pattern entails an increase in all these parameters between $12 \%$ and $72 \%$. Therefore, the Mediterranean diet is not only a cultural element and a health guard, but also an environmentally friendly dietary model. The only thing that we have to do in our case is to return to our traditional cuisine [19].

\section{The Mediterranean Diet as an Example in Environmental Education}

The goal of an environmental education program for formal education for the environment and sustainability using as a "vehicle" the Mediterranean diet should follow an interdisciplinary-holistic approach. Through the process of implementing its activities, learners are encouraged to increase their knowledge of the Mediterranean environment and development in the region as well as the Mediterranean diet in order to gain a more holistic view of modern trends and environmentally friendly attitudes. In essence, however, we are trying to change behavior and thinking "to formulate a code of conduct for each individual about environmental quality problems" [20] in accordance with the general principle of environmental education.

Through this logic, the objectives of the training material are to understand the dependence between environmental quality and the quality of the food produced, to assess the multiple negative 
environmental consequences of over-consumption, waste and poor management of the production, disposal, consumption and disposal of associated rubbish, to relate the consumption of certain foods to their health status and quality of their life [21]. This allows and encourages participation in creative action, reflection, ability to talk, cultivation of creative thinking but mainly the process of learning and acting [22]. Therefore, in order for the methodological model to work, a suggestion is to teach structure in four axes: (a) Information-Awareness, (b) Behavior-Stress Values, (c) Skills, (d) Participation.

\subsection{Information-Awareness}

In order to solve environmental problems, the task force has gained more and more experiential experiences on the issue of Mediterranean diet and environment, planning focuses on environmental problems due to various factors. Information topics are all those elements that have already been analyzed in the theoretical part: (1) Agriculture and food production; (2) Livestock farming; (3) The food industry; (4) Food transport and delivery to the consumer; (5) The last problem remains the loss and waste of food.

The information should be combined with awareness-raising on those points that prevail over the Mediterranean diet and are: (1) Contributing to maintaining and improving health; Understanding the fact that nutrition is directly linked to the agricultural products of each region; their range with the local environment (soil, climate and biodiversity) and the social environment; (2) The common cultural good. The emergence of the common nutritional choices of the Mediterranean peoples' due to the products produced in the Mediterranean environment, despite the cultural differences [23].

\subsection{Behavior}

A basic principle of awareness includes the incorporation of ethical values about the environment and their transformation from theory to practice. The goal is to achieve sustainability in the development of society. Besides, the term sustainability reflects the need for a careful balance between economic development and environmental protection. By defining what is sustainability, we can simply say that it usually refers to meeting the needs of the present generation without jeopardizing the needs of future generations [24]. The process of change must be done through the spiritual stimulation of learners and the promotion of free expression. However, by asking them questions about the environment, trainees should get into a new logic. This logic can be achieved through questions that direct thought and imagination into value-based structures of environmental education. The trainer in a group trying to create the bases for moral values must not impose but evoke, and that can easily be done through questions. Thus, opinions will be freely expressed in order to record, discuss and analyze possible interdependencies [24].

\subsection{Skills Development}

Skill development can not only be done through formal education. Not only is it important to transfer, but above all to transmit and thus to lead. It is therefore necessary for the instructor to have the belief or perception of what is right and what is not, what is right and what is wrong. According to Kant, man has the universal law inherent in them, but this idea cannot be considered as established [25].

The skills development can be experimented with experimental activities (experiments, analog experiments, simple constructions and preparations), bibliographic research (in textbooks, libraries, media, internet), analysis of information from texts, pictures in the educational material, opinion polls and informative action, role plays, endoscopy and redefinition of human relationships with nature. Teaching can create a strong ethical culture that will influence the actions and actions of the members of a group [26]. 


\subsection{Participation}

According to the International Conference on the Natural Environment, participation in environmental education includes the basis for the principle of sustainability: "Sustainability education is a lifelong learning process that leads to the creation of informed and active citizens, have the skills of creative problem solving, have scientific and social literacy and devotion to be able to engage in individual and collective responsible actions that will help ensuring a future with economic prosperity and environmental soundness." The radical change in attitude and attitude redefines the relation of man to the natural environment [27]. With the student's participation in the program, he will become the first attempt to conquer apocalyptic knowledge, develop knowledge, shape his character, personality, and generally acquire a positive attitude of life combining food and environment.

\section{Conclusion}

It is a fact that environmental education is trying to shape characters and moral behaviors that will give the environment opportunities and the person himself to maintain a better quality of life. What exactly has been formulated as a concept in environmental education has by definition been practiced in the Mediterranean diet. The peoples of the Mediterranean have shaped for centuries a cultural asset of respect for the natural environment that seeks to improve human health but also maintain a balance in the natural environment.

Through the learning process, knowledge about this asset can create an instructive learning action relationship for the sustainability and sustainable development both through formal education and non-formal education. The Mediterranean diet is a kind of environmental behavior that has an experiential character. For these reasons, it can by no means have an effect if the teaching is done by academic criteria only.
Finally, the Mediterranean diet does not attempt to impose or overturn any other cultural commodity but “asks” everyone to formulate a nutritional behavior that protects the natural environment but also human health.

\section{Reference}

[1] Agorastakis, G., and Michelakis, N. 2013. "Cretan and Mediterranean Diet, Similarities and Differences.” In Traditional Cretan Nutrition and Its Evolution. The Association of Cretan Olive Municipalities, pp. 16-7.

[2] Psillakis, N. 2001. Cretan Cuisine. Karmanor, p. 16.

[3] UNESCO. 2010. Representative List of Intangible Cultural Heritage of Humanity.

[4] Widmer, R. J., Flammer, A. J., Lerman, L. O., and Lerman, A. 2015. "The Mediterranean Diet, Its Components, and Cardiovascular Disease.” The American Journal of Medicine 128 (3): 229-38.

[5] Hardman, R. J., Kennedy, G., Macpherson, H., Scholey, A. B., and Pipingas, A. 2016. "Adherence to a Mediterranean-Style Diet and Effects on Cognition in Adults: A Qualitative Evaluation and Systematic Review of Longitudinal and Prospective Trials." Frontiers in Nutrition 3: 22. doi: 10.3389/fnut.2016.00022.

[6] Esposito, K., Kastorini, C.-M., Panagiotakos, D. B., and Giugliano, D. 2011. "Mediterranean Diet and Weight Loss: Meta-Analysis of Randomized Controlled Trials.” Metabolic Syndrome and Related Disorders 9: 1-12.

[7] Trichopoulou, A., Costacou, T., Bamia, C., and Trichopoulos, D. 2003. "Adherence to a Mediterranean Diet and Survival in a Greek Population.” The new England Journal of Medicine 348 (26): 2599-608.

[8] Hobbs, M., Pearson, N., Foster, P. J., and Biddle, S. J. H. 2015. "Sedentary Behavior and Diet across the Lifespan: An Updated Systematic Review.” Br. J. Sports Med. 49: 1179-88.

[9] Morris, C., and Winter, M. 1999. "Integrated Farming Systems: The Third Way for European Agriculture?” Land Use Policy 16: 193-205.

[10] Carlsson-Kanyama, A., and González, A. D. 2009. "Potential Contributions of Food Consumption Patterns to Climate Change.” The American Journal of Clinical Nutrition 89 (5): 1704S-9S.

[11] Serra-Majem, L., Ortiz-Andrellucchi, A., Ruan-Rodriguez, C., and Sánchez- Villegas, A. 2016. "The Mediterranean Diet as an Example of Environmental Sustainability.” Journal of Environment and Health Science 2 (5): 116-9. doi.org/10.15436/2378-6841.16.1098.

[12] Deutsch, L., Falkenmark, M., Gordon, L., Rockström, J., 
and Folke, C. 2010. "Water-Mediated Ecological Consequences of Intensification and Expansion of Livestock Production." In Livestock in a Changing Landscape. Vol. 1: Drivers, Consequences, and Responses, Edited by Steinfeld, H., Mooney, H. A., Schneider, F., and Neville, L. E. Washington, DC: Island Press, pp. 97-110.

[13] Galka, A. 2004. "Using a Cleaner Production Preventive Strategy for the Reduction of the Negative Environmental Impacts of Agricultural Production Using Cattle Husbandry as a Case Study." Journal of Cleaner Production 12: 513.

[14] Food and Agriculture Organization of the United Nations Rome. 2017. "Competition for Natural Resources.” In The Future of Food and Agriculture Trends and Challenges, pp. 46-9.

[15] Hecht, J. 1997. The Environmental Effects of Freight, Organization for Economic Co-operation and Development, Paris, pp. 11-29.

[16] Storup, K., Mattfolk, K., Voinea, D., Jakobsen, B., Bain, M., Reverté Casas, M. E., and Oliveira, P. 2016. "Combating Food Waste: An Opportunity for the EU to Improve the Resource-Efficiency of the Food Supply Chain.” European Court of Auditors 34: 6-7.

[17] Lindenmayer, J. M., and Schlaff, A. L. 2008. "The Combined Master of Public Health Program at Tufts University.” J. Vet. Med. Educ. 35 (2): 182-6. doi: 10.3138/jvme.35.2.182.

[18] Dernin, S., and Berry, E. M. 2015. "Mediterranean Diet: From a Healthy Diet to a Sustainable Dietary Pattern.” Frontiers in Nutrition 2: 15. doi: 10.3389/fnut.2015.00015.

[19] Serra-Majem, L., Ortiz-Andrellucchi, A., Rodriguez, C.
R., and Sanchez-Villegas, A. 2013. "Environmental Footprints of Mediterranean versus Western Dietary Patterns: Beyond the Health Benefits of the Mediterranean Diet.” Environmental Health 12: 118. doi: 10.1186/1476-069X-12-118.

[20] I.U.C.N., ed. 1970. International Working Meeting on Environmental Education in the School Curriculum. Carson City, Nevada, U.S.A., June/July 1970.

[21] James, W. P. T., Ferro-Luzzi, A., Isaksson, B., and Szostak, W. B. 1988. "Healthy Nutrition: Preventing Nutrition Related Diseases in Europe.” World Health Organization Regional Publications, European Series, Copenhagen, No. 24.

[22] Leitzmann, C. 2003. "Nutrition Ecology: The Contribution of Vegetarian Diets.” The American Journal of Clinical Nutrition 78 (3): 657S-9S.

[23] Trichopoulou, A., et al. 1997. "Nutrition in Europe: Nutrition Policy and Public Health in the European Community and Models for European Eating Habits on the Threshold of the 21st Century. Scientific and Technological Options Assessment (STOA).” European Parliament, Directorate General for Research, Luxembourg.

[24] Todaro, M. P., and Smith, S. C. 2006. Economic Development, 10th ed. Essex, p. 481.

[25] Guillermit, L. 2008. Leçons sur la "Critique de la raison pure”. Edited by de Kant. Paris: VRINS, pp. 60-1.

[26] Mondy, R. W., and Martocchio, J. J. 2016. Human Resource Management, 14th ed. Pearson Education Limited, p. 46.

[27] UNESCO. 2010.Teaching and Learning for a Sustainable Future. 